\title{
SEOM clinical guideline for the diagnosis and treatment of gastric cancer (GC) and gastroesophageal junction adenocarcinoma (GEJA) (2019)
}

\author{
M. Martín-Richard ${ }^{1}$ (1) - A. Carmona-Bayonas ${ }^{2}$ - Ana. B. Custodio ${ }^{3} \cdot$ J. Gallego $^{4} \cdot$ P. Jiménez-Fonseca ${ }^{5} \cdot$ J. J. Reina $^{6}$. \\ P. Richart ${ }^{7} \cdot$ F. Rivera ${ }^{8} \cdot$ M. Alsina ${ }^{9} \cdot$ J. Sastre ${ }^{10}$
}

Received: 30 November 2019 / Accepted: 30 November 2019 / Published online: 27 January 2020

(c) The Author(s) 2020

\begin{abstract}
Gastric cancer (GC) is the fifth most common cancer worldwide with a varied geographic distribution and an aggressive behavior. In Spain, it represents the sixth cause of cancer death. In Western countries, the incidence is decreasing slightly, with an increase in gastroesophageal junction adenocarcinoma (GEJA), a different entity that we separate specifically in the guideline. Molecular biology advances have been done recently, but do not yet lead to the choice in treatment approach except in advanced disease with overexpression of HER2. Endoscopic resection in very early stage, perioperative chemotherapy in locally advanced tumors and preliminary immune therapy resulting in advanced disease are the main treatment innovations in the GC/GEJA treatment. We describe the different evidences and recommendations following the statements of the American College of Physicians.
\end{abstract}

Keywords Gastric cancer · Gastroesophageal junction adenocarcinoma · Diagnosis · Treatment

M. Martín-Richard

mmartinri@santpau.cat

A. Carmona-Bayonas

alberto.carmonabayonas@gmail.com

Ana. B. Custodio

anabcustodio@gmail.com

J. Gallego

j.gallegoplazas@gmail.com

P. Jiménez-Fonseca

palucaji@hotmail.com

J. J. Reina

juanjoreinaz@yahoo.es

P. Richart

paularichart@gmail.com

F. Rivera

fernando.rivera@scsalud.es

M. Alsina

malsinamaqued@gmail.com

J. Sastre

jsastrev@salud.madrid.org

1 Medical Oncology Department, Hospital de la Santa Creu I Sant Pau, Sant Antoni Maria Claret, 167, 08025 Barcelona, Spain
2 Medical Oncology Department, Hospital J.M. Morales Meseguer, Murcia, Spain

3 Medical Oncology Department, Hospital Universitario La Paz, Centro de Investigación Biomédica en Red Cáncer, CB16/12/00398 Madrid, Spain

4 Medical Oncology Department, Hospital General Universitario de Elche y Vega Baja, Alicante, Spain

5 Medical Oncology Department, Hospital Universitario Central de Asturias, Oviedo, Spain

6 Medical Oncology Department, Hospital Universitario Virgen Macarena, Sevilla, Spain

7 Medical Oncology Department, Hospital Universitari I Politècnic la Fe, Valencia, Spain

8 Medical Oncology Department, Hospital Marqués de Valdecilla, IDIVAL, Santander, Spain

9 Medical Oncology Department, Hospital Universitario Vall D'Hebron, Universitat Autònoma de Barcelona (UAB), Barcelona, Spain

10 Medical Oncology Department, Hospital Clínico Universitario San Carlos, Madrid, Spain 


\section{Introduction}

Globally, gastric cancer (GC) is an important worldwide public health concern; it is the third cause of cancer mortality (after lung and colorectal cancer) and the fifth in incidence. There is a great variability in this incidence, with the highest values in East Asia, East Europe and in South America. In Spain, the estimated incidence of GC in 2019 is 7865 cases (ninth most frequent neoplasm), with higher incidence in men [1] as in the rest of the Western countries. The incidence of GC has gradually decreased over the last decade by $33 \%$ since 1980 . This decrease is probably related to the modification of some risk factors of GC: changes in diet, decrease in the incidence of helicobacter pylori (HP) infection and tobacco/alcohol consumption [2]. Other nonintervention risk factors that have been shown to be associated with GC are age, sex and genetic predisposition. The main familial syndrome associated with GC predisposition is the diffuse hereditary GC caused by mutations in the E-cadherin gene. In contrast, the incidence of gastroesophageal junction adenocarcinoma (GEJA) has increased over time in Western countries mainly due to risk factors such as obesity and gastroesophageal reflux [3]. GEJA is divided into three subtypes according to the Siewert classification and has often been grouped together with GC in randomized clinical trials.

In Europe, the GC is usually diagnosed at advanced stages. There are no screening programs for early detection, mainly due to the low-to-moderate incidence compared to the incidence in East Asia.

From the histological perspective, the vast majority of them $(85 \%)$ are adenocarcinomas. The two classic histological Lauren subtypes were intestinal and diffuse with different epidemiological, genetic and prognostic profiles. The WHO classification recognized five subtypes: papillary, tubular, mucinous, poorly cohesive (with or without signet ring cells) and mixed.

\section{Surveillance}

The available studies on resected GC follow-up are retrospective, without scientific evidence to improve survival. However, most international scientific societies recommend follow-up, although there is no agreement in the tests used or in the frequency [4]. The most sensitive test is the computed tomography (CT) scan with a sensitivity and a specificity of 60-90\%. Positron emission tomography (PET) may improve its results, when the results of the CT scan are doubtful. Follow-up with digestive endoscopy has limited utility, given the very small number of resectable local recurrences in GC [5]. The most promising research pathways in GC follow-up are based on stratifying patients by risk factors and the use of biomarkers.

\section{Molecular classification and emerging therapies}

The biology of GC is heterogeneous. Multiple deregulated canonical signaling pathways are known, involving p53, RAS, Wnt and various transcription factors, among others. In addition, $>30$ focal amplifications in oncogenes such as HER2, CCNE1, KRAS, MYC, EGFR, CDK6, GATA4, GATA6 and ZNF217 have been described. Genetic alterations tend to be framed in subtypes, making it easier to search for targetable driver genes. The Cancer Genome Atlas (TCGA) classification [6] divides gastric tumors into four subtypes: related to Epstein-Barr virus (EBV) (9\%), microsatellite instability (MSI) (22\%), genomically stable $(20 \%)$ and tumors with chromosomal instability (CIN) (50\%). Each subtype has a peculiar biology and specific genetic aberrations. Thus, in localized GC, the frequency of MSI is $8 \%$, being associated with lower sensitivity to fluoropyrimidines. HER2 amplifications occur in 9-36\% and predict prognosis and sensitivity to anti-HER 2 agents. There are other classifications with common but not equivalent traits, such as Singapore, or Asian Cancer Research Group (ACRG) classifications [7, 8]. In addition to identifying new targets, these findings open the door to the development of predictive and prognostic biomarkers. Several have been proposed, such as Immunoscore, detection of circulating tumor DNA (ctDNA) and others. Their superior performance with respect to well-established clinical-pathological factors, such as Lauren's classification or the AGAMENON model, is pending confirmation $[9,10]$.

These advances have potential therapeutic implications. Immune checkpoint inhibitors could be effective, although the benefit has not yet been fully demonstrated in the first or second line Finally, as a result of molecular characterization, clinical trials are currently being carried out with PI3K/AKT/mTOR, VEGFR or HER2 signaling pathways inhibitors, and other novel targets are being explored, such as ARID1A, Claudin 18.2 (a component of tight junctions), matrix metalloproteinase-9, PARP or cancer stem cells inhibitors.

\section{Diagnosis and staging}

Gastroscopy is the primary diagnostic tool for GC. Biopsies of suspicious lesions should always be taken in order to confirm histology and to classify GC according to the World Health Organization (WHO) criteria and Lauren classification HER2 testing, which should be conducted with the aim 
of selecting patients with metastatic disease for treatment with trastuzumab-containing regimen (E: high; R: strong). Polymerase chain reaction (PCR) for microsatellite instability (MSI) or immunohistochemistry (IHC) for mismatch repair deficiency (dMMR) should be tested on advanced $\mathrm{GC}$ with a view to predicting the clinical benefit of immune checkpoint inhibitors (CPIs) (E: moderate; R: strong). Programmed death ligand 1 (PD-L1) may be considered as potential biomarker for the use of CPIs [11].

Endoscopic ultrasonography (EUS) is helpful in the preoperative staging of GC to evaluate the depth of invasion of tumor and the presence of local lymph node metastases and is recommended if early versus locally advanced disease needs to be determined [12] (E: moderate; R: strong). CT scan of the thorax, abdomen and pelvis is mandatory in preoperative staging of GC. In some patients, PET-CT may improve staging by detecting metastatic disease not visible with other explorations [13]; however, PET-CT may not be informative in patients with mucinous or diffuse tumors (E: moderate; R: weak). Diagnostic laparoscopy is recommended in resectable GC with clinical T3 and T4 cancers or in those at higher risk for metastatic disease, such as poorly differentiated cancers and those with a higher nodal burden [14] (E: moderate; R: strong). The cytological examination of peritoneal lavage, although limited by a low sensitivity, may help identify occult carcinomatosis. Staging is performed according to the 2017 AJCC TNM classification, 8th edition (Tables 1,2). All patients diagnosed with GC or GEJA should be discussed at a multidisciplinary team meeting.

\section{Treatment}

\section{Endoscopic resection}

In some selected cases of early GC, endoscopic therapy can be used as an alternative to gastrectomy for lesions that have a very low risk of lymph node metastasis. This approach can be performed in high-volume medical centers with extensive experience in these techniques. Endoscopic submucosal dissection (ESD) has been shown to be more effective than endoscopic mucosal resection (EMR), but requires greater skill and is associated with higher rates of perforation. The classic absolute indications of EMR/ESD include lesions limited to the mucosa (T1a), well to moderately differentiated adenocarcinomas, tumors $\leq 2 \mathrm{~cm}$ in diameter, absence of ulceration and lymphovascular involvement. Additional treatment is sometimes required based on definitive pathological results (E: moderate; R: strong).
Table 1 AJCC prognostic stage groups pathological staging (pTNM) GC

Table 2 AJCC prognostic stage groups pathological staging (pTNM) GEJA

\begin{tabular}{|c|c|c|c|}
\hline 0 & Tis & N0 & M0 \\
\hline IA & $\mathrm{T} 1$ & N0 & M0 \\
\hline \multirow[t]{2}{*}{ IB } & $\mathrm{T} 1$ & N1 & M0 \\
\hline & $\mathrm{T} 2$ & No & M0 \\
\hline \multirow[t]{3}{*}{ IIA } & $\mathrm{T} 1$ & $\mathrm{~N} 2$ & M0 \\
\hline & $\mathrm{T} 2$ & N1 & M0 \\
\hline & $\mathrm{T} 3$ & N0 & M0 \\
\hline \multirow[t]{4}{*}{ IIB } & $\mathrm{T} 1$ & $\mathrm{~N} 3 \mathrm{a}$ & M0 \\
\hline & $\mathrm{T} 2$ & N2 & M0 \\
\hline & T3 & N1 & M0 \\
\hline & $\mathrm{T} 4 \mathrm{a}$ & No & M0 \\
\hline \multirow[t]{5}{*}{ IIIA } & $\mathrm{T} 2$ & N3a & M0 \\
\hline & $\mathrm{T} 3$ & N2 & M0 \\
\hline & $\mathrm{T} 4 \mathrm{a}$ & N1 & M0 \\
\hline & $\mathrm{T} 4 \mathrm{a}$ & N2 & M0 \\
\hline & $\mathrm{T} 4 \mathrm{~b}$ & No & M0 \\
\hline \multirow[t]{6}{*}{ IIIB } & $\mathrm{T} 1$ & N3b & M0 \\
\hline & $\mathrm{T} 2$ & $\mathrm{~N} 3 \mathrm{~b}$ & M0 \\
\hline & $\mathrm{T} 3$ & $\mathrm{~N} 3 \mathrm{a}$ & M0 \\
\hline & $\mathrm{T} 4 \mathrm{a}$ & $\mathrm{N} 3 \mathrm{a}$ & M0 \\
\hline & $\mathrm{T} 4 \mathrm{~b}$ & N1 & M0 \\
\hline & $\mathrm{T} 4 \mathrm{~b}$ & N2 & M0 \\
\hline \multirow[t]{4}{*}{ IIIC } & $\mathrm{T} 3$ & $\mathrm{~N} 3 \mathrm{~b}$ & M0 \\
\hline & $\mathrm{T} 4 \mathrm{a}$ & $\mathrm{N} 3 \mathrm{~b}$ & M0 \\
\hline & $\mathrm{T} 4 \mathrm{~b}$ & $\mathrm{~N} 3 \mathrm{a}$ & M0 \\
\hline & $\mathrm{T} 4 \mathrm{~b}$ & $\mathrm{~N} 3 \mathrm{~b}$ & M0 \\
\hline IV & Any $\mathrm{T}$ & Any N & M1 \\
\hline
\end{tabular}

\begin{tabular}{lllll}
\hline 0 & Tis & N0 & M0 & N/A \\
\hline IA & T1A & N0 & MO & G1, X \\
IB & T1a & N0 & M0 & G2 \\
& T1b & N0 & M0 & G1-2 \\
IC & T1 & N0 & M0 & G3 \\
& T2 & N0 & M0 & G1-2 \\
IIA & T2 & N0 & M0 & G3 \\
IIB & T1 & N1 & M0 & Any \\
& T3 & N0 & M0 & Any \\
IIIA & T1 & N2 & M0 & Any \\
& T2 & N1 & M0 & Any \\
IIIB & T4 & N0-1 & M0 & Any \\
& T3 & N1 & M0 & Any \\
& T2-3 & N2 & M0 & Any \\
IVA & T4a & N2 & M0 & Any \\
& T1-4 & N3 & M0 & Any \\
& T1-4 & N0-3 & M1 & Any \\
\hline N/A & not & applicable, & $X$ \\
defined & & &
\end{tabular}




\section{Surgery}

Complete resection with adequate margins remains the cornerstone of curative treatment of resectable stage I-III GC. Experienced surgical teams generally consider unresectable tumors that invade: pancreatic head, hepatic hilum, transverse mesocolon, mesenteric artery or aorta.

The type of resection in GC, subtotal vs total gastrectomy, depends on anatomic location of primary tumor. For GEJA, a total esophagectomy with a partial gastrectomy or an extended gastrectomy is generally performed.

Extent of lymph node dissection remains controversial, while there is consensus that lymphadenectomy should include at least 15 nodes. In Western countries, two large RCTs and a meta-analysis of 12 RCTs failed to demonstrate an OS benefit for D2 over D1 lymph node dissection. However, mature follow-up data from the Dutch trial showed a lower locoregional recurrence rate and fewer GC-related death with D2 lymphadenectomy, and the meta-analysis found a benefit among patients who had resection without splenectomy and/or pancreatectomy [15].

Gastrectomy with D2 lymph node dissection is a recommended procedure in patients with good PS whenever it is carried out in specialized centers, with experienced surgeons and a high-volume interventions (E: high; R: strong). Routine pancreatectomy and splenectomy are no longer recommended with D2 lymph node dissection (E: moderate; R: strong).

\section{Neoadjuvant treatment}

\section{Chemotherapy (CT)}

A RCT by the EORTC (40954) in 144 patients with stage III-IV (M0) GC or GEJA found a significantly higher rate of $\mathrm{R} 0$ resection among patients receiving neoadjuvant $\mathrm{CT}$
(Cisplatin and 5FU : CF); however, no difference in OS was reached. At present, as more contrasted alternatives are available, this treatment should only be considered within a clinical trial [16].

\section{Chemoradiotherapy (CRT)}

The phase III POET study compared two preoperative treatments, $\mathrm{CT}$ (CF, 15 weeks) vs CT (CF, 12 weeks) followed by CRT (Cisplatin and Etoposide plus 30 Gy of RT, 3 weeks) in patients with uT3-4NXM0 adenocarcinoma of the lower esophagus or gastric cardia [17]. Although the study was closed early and statistical significance was not achieved, results point to a survival advantage for preoperative CRT compared with CT in GEJA.

The phase III CROSS trial compared neoadjuvant CRT (Carboplatin and Paclitaxel of RT, 5 weeks) versus surgery alone in patients with T1N1M0 or T2-3N0-1M0 squamous cell carcinoma (SCC) and adenocarcinoma of the esophagus or GEJA [18]. Ninety-five percent were able to complete the entire neoadjuvant CRT with a significant increase of OS in this group.

Neoadjuvant CRT followed by resection is preferred than neoadjuvant chemotherapy and could be an alternative to perioperative chemotherapy approach for $\mathrm{T} 1 \mathrm{~N} 1$ or T2-3N0-1M0 GEJA (E: high; R: strong).

\section{Perioperative treatment}

Perioperative CT for GC and GEJA was shown to significantly increase disease-free survival (DFS) and overall survival (OS) as compared to surgery alone in two landmark phase 3 trials conducted in Western countries: the MAGIC trial, in which patients received three cycles of Epirrubicin, Cisplatin and Fluorouracil (ECF) before and after surgery [19], and the ACCORD-07 using perioperative Cisplatin and

Table 3 Phase III trials of perioperative chemotherapy in gastric and gastroesophageal junction adenocarcinoma

\begin{tabular}{|c|c|c|c|c|}
\hline Study & N/N GEJC & Design & 5-year DFS/PFS & 5-year OS \\
\hline \multirow[t]{2}{*}{ MAGIC (1) } & \multirow[t]{2}{*}{$503 / 58$} & Surgery & & $23 \%$ \\
\hline & & $\mathrm{ECF} \times 3 \rightarrow$ Surgery $\rightarrow \mathrm{ECF} \times 3$ & $\begin{array}{l}\text { NR } \\
\text { HR: } 0.66(95 \% \text { CI } 0.53-0.81)\end{array}$ & $\begin{array}{l}36.3 \% \\
\text { HR: } 0.75 \text { (95\% CI } 0.60-0.93)\end{array}$ \\
\hline \multirow[t]{2}{*}{ FFCD ACCORD-7 (2) } & \multirow[t]{2}{*}{$224 / 144$} & Surgery & $19 \%$ & $24 \%$ \\
\hline & & $\mathrm{CF} \times 2 \rightarrow$ Surgery $\rightarrow \mathrm{CF} \times 2$ & $\begin{array}{l}34 \% \\
\text { HR: } 0.65 \text { (95\% CI } 0.48-0.89)\end{array}$ & $\begin{array}{l}38 \% \\
\text { HR: } 0.69 \text { (95\% CI } 0.50-0.95)\end{array}$ \\
\hline \multirow[t]{2}{*}{ FLOT4-AIO (4) } & \multirow[t]{2}{*}{$716 / 398$} & $\mathrm{ECF} / \mathrm{ECX} \times 3 \rightarrow$ Surgery $\rightarrow \mathrm{ECF} / \mathrm{ECX} \times 3$ & $31 \%$ & $36 \%$ \\
\hline & & FLOT $\times 4 \rightarrow$ Surgery $\rightarrow$ FLOT 4 & $\begin{array}{l}41 \% \\
\text { HR: } 0.75(95 \% \text { CI } 0.62-0.91)\end{array}$ & $\begin{array}{l}45 \% \\
\text { HR: } 0.77 \text { (95\% CI } 0.63-0.94)\end{array}$ \\
\hline
\end{tabular}

$N$ number of patients, GEJC gastroesophageal junction cancer, $D F S$ disease-free survival, $P F S$ progression-free survival, $O S$ overall survival, ECF Epirubicin, Cisplatin and 5-Fluorouracil, $C F$ Cisplatin and 5-Fluorouracil, ECX Epirubicin, Cisplatin and Capecitabine, FLOT 5-Fluorouracil, Leucovorin, Oxaliplatin and Docetaxel, $N R$ not reported, $H R$ hazard ratio, 95\% CI 95\% confidence interval 
Fluorouracil CT [20]. A higher R0 rate was also observed in the last study (Table 3).

\section{Adjuvant treatment}

When surgery is adopted as first treatment approach for localized GC, adjuvant CT or CRT may be considered.

The benefit of FU-based adjuvant $\mathrm{CT}$ versus surgery alone was initially suggested in an individual patient-level metaanalysis (OS: HR 0.82, $p<0.01$; DFS: HR $0.80, p<0.06$ ) based on old randomized studies [23]. Subsequently, S-1 and CAPOX (Capecitabine and Oxaliplatin) both showed statistically significant benefit in DFS and OS compared to observation after D2 resection of stage II or III GC [24]. Recently, the addition of Docetaxel to $S 1$ showed better results than $\mathrm{S} 1$ alone in terms of DFS after D2 resection for stage III GC [4]. Hence, even though data come from trials performed in Asian population, adjuvant chemotherapy in resected GC can be considered (E: moderate; R: strong). The particular benefit of this strategy in patients with dMMR GC harboring has become controversial after limited subgroup analysis in this adjuvant and other perioperative clinical trials.

The first phase III randomized trial to demonstrate benefit of adjuvant RCT) compared to observation after surgery in stage IB-IV GC was INT-0116 (OS: HR 1.3-2, $p=0.005$; DFS: HR 1.51, $p<0.001$ [25]. Nevertheless, this trial was criticized due to quality of surgery, CT regimen and radiotherapy (RT) planning. The attempt to improve these results with ECF (Epirubicin, Cisplatin, 5FU) instead of the classic Mayo regimen before and after RT was shown to be futile in the CALGB 80101 trial. In order to compare adjuvant CT versus $C R$, the phase III ARTIST trial randomized patients after D2-resected GC to adjuvant Cisplatin and Capecitabine with or without Capecitabine-based RT. Only DFS benefit was suggested for node-positive and intestinal-type disease in subgroup analysis [26]. Phase III, three-arm, ARTIST II trial, including these and other questions in its design, has not been able to set firm conclusions so far in this regard. Considering these results, adjuvant CRT can be established after D0-resected stage IB-IV GC (E: moderate; R: strong). The CT regimen to be used before and after RT and the CT partner during RT are still topics of discussion.

\section{Advanced disease: First-line treatment}

Chemotherapy CT has shown improved OS and quality of life in patients with advanced gastric cancer (E: high; R: strong).

The most commonly used regimens for the first-line treatment are doublets of a Platinum and a Fluoropyrimidine, which have demonstrated superiority to other schemes without Platinum (E: high; R: strong). Both Oxaliplatin and Cisplatin are suitable options (E: high; R: strong) [27]; and
5FU, Capecitabine and S1 are acceptable options (E: high; R: strong) [27, 28].

Triplet combinations of Docetaxel, Platinum and Fluoropyrimidines may be more active than doublet regimens and could be an acceptable option only for fit patients and if a quick response is needed (E: moderate; R: weak) because they add considerable toxicity [29]. On the other hand, the benefit of adding Epirubicin to the Platinum and Fluoropyrimidine doublet is nowadays not recommended (E: moderate; R: weak).

As an alternative to a Platinum-based treatment in the first-line setting, a doublet of Irinotecan and 5FU might be considered (E: moderate; R: strong).

Anti-HER-2 HER 2 is overexpressed (IHC $3+$ or IHC $2+$ with FISH+) in 13-25\% of patients with GC, being more frequently found in tumors of the intestinal type and those located in the GEJA. The pivotal study performed showed the superiority of the combination of CT (Cisplatin, 5FU or Capecitabine) and Trastuzumab in front of CT. An increase in radiological ( $47 \%$ vs $35 \%, p<0.001)$, PFS ( 6.7 vs $5.5 \mathrm{~m}$, HR $0.71, p<0.001)$ and OS (13.8 vs 11.1 months, HR 0.74 , $p$ 0.005) was observed. Therefore, this combination is the standard of care in the first-line treatment in HER2-overexpressing tumors (E: high; R: strong) [30]. Other anti-HER-2 therapies such as Lapatinib and Pertuzumab have not yet demonstrated a benefit in OS.

Other treatments Randomized trials with antiangiogenics (Bevacizumab, Ramucirumab and Sorafenib) did not show an improvement in OS in the first-line setting.

The results of the KEYNOTE-062 RCT were recently reported [31], which suggested that Pembrolizumab alone could be equally active and less toxic than $\mathrm{CT}$ as first-line treatment in patients with advanced GC or GEJA with PD-L1 positive tumors ( $\mathrm{CPS} \geq 1$ ) (E: moderate; R: weak). This study also suggests that the benefit of Pembrolizumab alone could be greater in the subgroup of patients with CPS $\geq 10$ (E: low; R: weak). Nevertheless, this trial did not demonstrate a significant benefit with the addition of Pembrolizumab to CT vs CT alone.

There are currently ongoing other phase III RCTs exploring the role of other immunotherapies and targeted therapies for the first-line treatment of advanced GC, most of them including a biomarker analysis that will probably be very important for a proper patient selection.

\section{Second- and third-line treatment and immunotherapy}

About $50 \%$ of the GC and GEJA patients are fit enough to receive a second-line treatment, being only the $20 \%$ in the case of the third line. However, the benefit of a second CT line (weekly Paclitaxel, Docetaxel or Irinotecan) has been 
Table 4 List of main phase II/ III clinical trials evaluating the (a) second- and (b) thirdline treatment for gastric and gastroesophageal junction cancer

\begin{tabular}{|c|c|c|c|c|c|}
\hline Clinical trial & $\mathrm{Ph}$ & $N$ & Treatment arm & Median OS & RR \\
\hline \multicolumn{6}{|l|}{ (a) Second-line setting } \\
\hline AIO Trial & III & 40 & Irinotecan & $4.0 \mathrm{~m}$ & $0 \%$ \\
\hline $\begin{array}{l}\text { Thuss-Patience } \\
\text { Eur J Can } 2011\end{array}$ & & & BSC & $\begin{array}{l}2.4 \mathrm{~m} \\
\text { HR } 0.48, p 0.012\end{array}$ & $0 \%$ \\
\hline $\begin{array}{l}\text { Salvage Chemo } \text { Trial }^{\mathrm{a}} \\
\text { Kang } \\
\text { J Clin Oncol } 2012\end{array}$ & III & 188 & $\begin{array}{l}\text { Doce/irinotecan } \\
\text { BSC }\end{array}$ & $\begin{array}{l}5.3 \mathrm{~m} \\
3.8 \mathrm{~m} \\
\text { HR } 0.65, p 0.007\end{array}$ & $\begin{array}{l}\text { Docetaxel } 16 \% \\
\text { Irinotecan } 1 \% \\
\text { BSC }\end{array}$ \\
\hline $\begin{array}{l}\text { COUGAR 02 } \\
\text { Ford } \\
\text { Lancet Oncol } 2014\end{array}$ & III & 168 & $\begin{array}{l}\text { Docetaxel } \\
\text { BSC }\end{array}$ & $\begin{array}{l}5.2 \mathrm{~m} \\
3.6 \mathrm{~m} \\
\text { HR } 0.67, p 0.01\end{array}$ & $\begin{array}{l}7 \% \\
0 \%\end{array}$ \\
\hline $\begin{array}{l}\text { WJOG4007 }^{\text {a }} \\
\text { Hironaka } \\
\text { J Clin Oncol } 2013\end{array}$ & III & 219 & $\begin{array}{l}\text { wPaclitaxel } \\
\text { Irinotecan }\end{array}$ & $\begin{array}{l}9.5 \mathrm{~m} \\
8.4 \mathrm{~m} \\
\text { HR } 1.13, p 0.38\end{array}$ & $\begin{array}{l}20.9 \% \\
13.6 \%\end{array}$ \\
\hline $\begin{array}{l}\text { RAINBOW } \\
\text { Wilke } \\
\text { Lancet Oncol } 2014\end{array}$ & III & 665 & $\begin{array}{l}\text { Pac-ramu } \\
\text { Paclitaxel }\end{array}$ & $\begin{array}{l}9.6 \mathrm{~m} \\
7.4 \mathrm{~m} \\
\text { HR } 0.80, p 0.017\end{array}$ & $\begin{array}{l}28 \% \\
16 \%\end{array}$ \\
\hline $\begin{array}{l}\text { REGARD } \\
\text { Fuchs } \\
\text { Lancet } 2014\end{array}$ & III & 355 & $\begin{array}{l}\text { Ramucirumab } \\
\text { Placebo }\end{array}$ & $\begin{array}{l}5.2 \mathrm{~m} \\
3.8 \mathrm{~m} \\
\text { HR } 0.77, p 0.047\end{array}$ & $\begin{array}{l}3 \% \\
3 \%\end{array}$ \\
\hline $\begin{array}{l}\text { TyTAN } \\
\text { Satoh } \\
\text { J Clin Oncol } 2014\end{array}$ & III & 261 & $\begin{array}{l}\text { Pac + lapatinib } \\
\text { Paclitaxel }\end{array}$ & $\begin{array}{l}11.0 \mathrm{~m} \\
8.9 \mathrm{~m} \\
\text { HR } 0.84, p 0.104\end{array}$ & $\begin{array}{l}27 \% \\
9 \%\end{array}$ \\
\hline $\begin{array}{l}\text { GATSBY } \\
\text { Thuss-Patience } \\
\text { Lancet Oncol } 2017\end{array}$ & III & 345 & $\begin{array}{l}\text { T-DM1 } \\
\text { Doce/Pac }\end{array}$ & $\begin{array}{l}7.9 \mathrm{~m} \\
8.6 \mathrm{~m} \\
\text { HR } 1.15, p 0.86\end{array}$ & $\begin{array}{l}20.6 \% \\
19.6 \%\end{array}$ \\
\hline $\begin{array}{l}\text { GOLD }^{\mathrm{a}} \\
\text { Bang } \\
\text { Lancet Oncol } 2017\end{array}$ & III & 643 & $\begin{array}{l}\text { Pac-Olaparib } \\
\text { Paclitaxel }\end{array}$ & $\begin{array}{l}8.8 \mathrm{~m} \\
6.9 \mathrm{~m} \\
\text { HR } 0.79, p 0.026\end{array}$ & $\begin{array}{l}17 \% \\
11 \%\end{array}$ \\
\hline $\begin{array}{l}\text { KEYNOTE-061 } \\
\text { Shitara } \\
\text { Lancet } 2018\end{array}$ & III & 592 & $\begin{array}{l}\text { Pembrolizumab } \\
\text { wPaclitaxel }\end{array}$ & $\begin{array}{l}9.1 \mathrm{~m} \\
8.3 \mathrm{~m} \\
\text { HR } 0.82, p 0.042\end{array}$ & $\begin{array}{l}16 \% \\
14 \%\end{array}$ \\
\hline (b) Third line setting and be & & & & & \\
\hline $\begin{array}{l}\text { TAGS } \\
\text { Shitara } \\
\text { Lancet Oncol } 2018\end{array}$ & III & 507 & $\begin{array}{l}\text { FTD/TPI } \\
\text { Placebo }\end{array}$ & $\begin{array}{l}5.7 \mathrm{~m} \\
3.6 \mathrm{~m} \\
\text { HR } 0.69, p<0.001\end{array}$ & $\begin{array}{l}4 \% \\
2 \%\end{array}$ \\
\hline $\begin{array}{l}\text { Apatinib Trial }^{\mathrm{a}} \\
\mathrm{Li} \\
\text { J Clin Oncol } 2016\end{array}$ & III & 267 & $\begin{array}{l}\text { Apatinib } \\
\text { Placebo }\end{array}$ & $\begin{array}{l}6.5 \mathrm{~m} \\
4.7 \mathrm{~m} \\
\text { HR } 0.70, p 0.015\end{array}$ & $\begin{array}{l}2.84 \% \\
0 \%\end{array}$ \\
\hline $\begin{array}{l}\text { GRANITE-1 } \\
\text { Othsu } \\
\text { J Clin Oncol } 2013\end{array}$ & III & 656 & $\begin{array}{l}\text { Everolimus } \\
\text { Placebo }\end{array}$ & $\begin{array}{l}5.4 \mathrm{~m} \\
4.3 \mathrm{~m} \\
\text { HR } 0.90, p 0.124\end{array}$ & $\begin{array}{l}4.5 \% \\
2.1 \%\end{array}$ \\
\hline $\begin{array}{l}\text { ATTRACTION-2 } \\
\text { Kang Lancet } 2017\end{array}$ & III & 493 & $\begin{array}{l}\text { Nivolumab } \\
\text { Placebo }\end{array}$ & $\begin{array}{l}5.26 \mathrm{~m} \\
4.14 \mathrm{~m} \\
\text { HR } 0.63, p<0.001\end{array}$ & $\begin{array}{l}11.2 \% \\
0 \%\end{array}$ \\
\hline $\begin{array}{l}\text { KEYNOTE-059 Cohort } 3 \\
\text { Fuchs JAMA Oncol } 2018\end{array}$ & II & 259 & Pembrolizumab & $5.5 \mathrm{~m}$ & $12 \%$ \\
\hline $\begin{array}{l}\text { JAVELIN } 300 \\
\text { Bang } \\
\text { Ann Oncol } 2018\end{array}$ & III & 371 & $\begin{array}{l}\text { Avelumab } \\
\text { Pac/Irinotecan }\end{array}$ & $\begin{array}{l}4.6 \mathrm{~m} \\
5.0 \mathrm{~m} \\
\text { HR } 1.1, p=0.81\end{array}$ & $\begin{array}{l}2.2 \% \\
4.3 \%\end{array}$ \\
\hline
\end{tabular}

$P h$ phase, $O S$ overall survival, $R R$ response rate, $B S C$ best supportive care, $H R$ hazard ratio, Doce Docetaxel, Pac Paclitaxel, Ramu Ramucirumab, FTD/TPI trifluridine/tipiracil

${ }^{\text {a }}$ Trials performed only in Asian population 
Table 5 Summary of evidences/ recommendations

Diagnosis and staging

\begin{tabular}{|c|c|c|c|}
\hline & & Case & $\begin{array}{l}\text { Evidence (E:) Recom- } \\
\text { mendation (R:) }\end{array}$ \\
\hline \multirow[t]{2}{*}{ Endoscopy + biopsies } & Mandatory & All & E: high; R: strong \\
\hline & Mandatory & All & \\
\hline HER2 determination by IHC/FISH & Mandatory & Metastatic stage & \\
\hline $\begin{array}{l}\text { Other molecular factors determination: } \\
\text { MSI }^{\mathrm{a}} \\
\mathrm{dMMR}^{\mathrm{b}}\end{array}$ & Useful & Metastatic stage & E: moderate; R: weak \\
\hline PDL1 expression & & $\begin{array}{l}\text { Consider CPI use } \\
= \\
=\end{array}$ & \\
\hline EUS & $\begin{array}{l}\text { Mandatory } \\
\text { Useful }\end{array}$ & $\begin{array}{l}\text { Early stage } \\
\text { All }\end{array}$ & E: high; R: strong \\
\hline CT thorax, abdomen, pelvis & Mandatory & All & E: high; R: strong \\
\hline PET-TC & Useful & All except diffuse AC & E: moderate; R: weak \\
\hline Laparoscopy & Mandatory & T3-4 or higher nodal burden AC & E: moderate; R: strong \\
\hline \multicolumn{4}{|l|}{ Treatment } \\
\hline Stage & Detail & Treatment & $\begin{array}{l}\text { Evidence (E:) Recom- } \\
\text { mendation (R:) }\end{array}$ \\
\hline \multicolumn{4}{|l|}{ Early stage (Tis-I) } \\
\hline Tis/T1a & $\begin{array}{l}\text { Well dif./2 cm/non-ulcerated/ } \\
\text { intestinal }\end{array}$ & Endoscopic resection & E: moderate; R: strong \\
\hline T1a & Others non-ulcerated & $\begin{array}{l}\text { Endoscopic resection (mucosectomy)/ } \\
\text { surgery }\end{array}$ & \\
\hline $\mathrm{T} 1 \mathrm{~b}$ & $\begin{array}{l}<3 \mathrm{~cm} \\
\text { Others }\end{array}$ & Submucosal resection/surgery & \\
\hline $\mathrm{T} 1 \mathrm{~b}$ & Others & Surgery & \\
\hline \multicolumn{4}{|l|}{ Locally advanced (Stage II-III) } \\
\hline \multirow[t]{4}{*}{ GEJA } & Neoadjuvant CT & E: moderate; R:weak & \\
\hline & or CRT (IA) & E: high; R: strong & \\
\hline & or Perioperative CT & E: high; R: strong & \\
\hline & or Adjuvant CRT & E: high; R: strong & \\
\hline \multirow[t]{4}{*}{ GC } & Neoadjuvant CT & E: moderate; R:weak & \\
\hline & or Perioperative CT & E: high; R: strong & \\
\hline & or Adjuvant CT & E:moderate; R: strong & \\
\hline & or Adjuvant CRT & E: moderate; R: strong & \\
\hline \multicolumn{4}{|l|}{ Advanced stage $(I V)^{\mathrm{c}}$} \\
\hline \multirow[t]{4}{*}{ First line } & HER $2+$ & & \\
\hline & Cisplatin-fluorop- Trastu & $\begin{array}{l}\text { E: high; R: strong } \\
\text { E: high; R: strong }\end{array}$ & \\
\hline & HER2- & $\begin{array}{l}\text { E: moderate; R:weak } \\
\text { E: moderate; R:weak }\end{array}$ & \\
\hline & $\begin{array}{l}\text { Platinum-fluorop } \\
\text { or ECF } \\
\text { or DCF } \\
\text { or FOLFIRI or IF }\end{array}$ & E: moderate; R:strong & \\
\hline \multirow[t]{5}{*}{ Second line } & Paclitaxel-ramucirumab & E: high; R: strong & \\
\hline & or Irinotecan & E: high; R: strong & \\
\hline & or Docetaxel & E: high; R: strong & \\
\hline & or Paclitaxel & E: high; R: strong & \\
\hline & or Ramucirumab & E: high; R: strong & \\
\hline Third line & Trifluridine/tipiracil & E: high; R: strong & \\
\hline
\end{tabular}

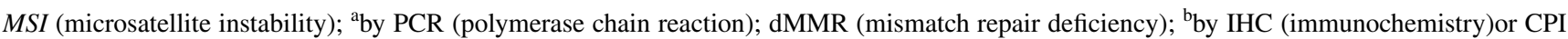
(checkpoint inhibitor); EUS (endoscopic sonography); $\mathrm{Ct}$ (computed tomography); and AC (adenocarcinoma)

'Platinum: Cisplatin or Oxaliplatin; Fluorop: Fluoropyrimidine (5Fu/Capecitabine); Trastu: trastuzumab; ECF: Epirubicin-Cisplatin-Fluoropyrimidine; and DCF: Docetaxel-Cisplatin-Fluoropyrimidine 
widely demonstrated in terms of survival and quality of life (E: high; R: strong). The RAINBOW RCT settled the combination of Paclitaxel and Ramucirumab as the preferred regimen [32] (E: high; R: strong). When considering a third line, small phase II clinical trials support its efficacy in patients with a good performance status (PS) (E: moderate; R: weak). The results from the recent randomized phase III TAGS RCT confirmed the benefit of a third CT line with trifluridine/ tipiracil, in terms of survival and time to ECOG/PS deterioration [4] (E: high, R: strong) (Table 4).

Despite the inflammatory carcinogenesis of GC/GEJC and the encouraging efficacy shown in preliminary studies, the effect of immunotherapy is questioned in the secondand third-line treatment due to disappointed results. The randomized phase III KEYNOTE-061 trial demonstrated a clinical benefit of Pembrolizumab against weekly Paclitaxel in patients with PD-L1 $\geq 1$ (CPS), although the differences were not statistically significant. In the third line, Nivolumab demonstrated an increase in OS compared with placebo; however, the study was performed exclusively in Asian population and results of patients from Western countries are awaited. Avelumab failed to demonstrate superiority in front of CT [33]. Nowadays, the immunotherapy can only be considered in the refractory setting, with Pembrolizumab in MSI patients given the high response rate achieved by these patients (57\%) in the phase II clinical trial KEYNOTE-059 (E: moderate; R: strong) [34]. The summary of evidences and recomendations of this Guideline is in Table 5.

\section{Compliance with ethical standards}

Conflict of interest MMR has nothing to disclose. JS reports honoraria for speaking from Merck, Roche, Servier, Lilly, Ipsen, Shire, Pfizer, Servier and MSD; advisory role from Roche, Amgen, Merck, Bayer, Celgene, Servier, BMS, Sanofi, Ipsen; and travel expenses from Merck and Ipsen. JG has nothing to disclose. PR has nothing to disclose. MA reports scientific consultancy from Servier, Lilly, BMS and MSD; honoraria for speaking from Servier, BMS, MSD, Lilly, Roche and Amgen; and travel expenses from Servier, Roche, Amgen and Lilly. JR reports personal fees from Roche and personal fees from Lilly, outside the submitted work. FR reports consultant or advisory role from Roche, Merck-Serono, Amgen, MSD, BMS, Lilly, Celgene, SanofiAventis, Servier, Astra-Zeneca and Bayer; research funding from Roche, Merck-Serono, Amgen, MSD, Lilly, Celgene, Sanofi-Aventis, Bayer and Servier; speaking from Roche, Merck-Serono, Amgen, MSD, BMS, Lilly, Celgene, Sanofi-Aventis, Servier and Bayer; and grant support from Amgen. PJF reports travel grants from Ipsen and Leo Pharma all outside the scope of this work. ABC has nothing to disclose. AC reports grants from BMS, Roche, Servier and Merck, outside the submitted work.

Ethical standards The current study has been performed in accordance with the ethical standards laid down in the 1964 Declaration of Helsinki and its later amendments.

Informed consent As clinical guideline, patient informed consent does not apply.
Open Access This article is licensed under a Creative Commons Attribution 4.0 International License, which permits use, sharing, adaptation, distribution and reproduction in any medium or format, as long as you give appropriate credit to the original author(s) and the source, provide a link to the Creative Commons licence, and indicate if changes were made. The images or other third party material in this article are included in the article's Creative Commons licence, unless indicated otherwise in a credit line to the material. If material is not included in the article's Creative Commons licence and your intended use is not permitted by statutory regulation or exceeds the permitted use, you will need to obtain permission directly from the copyright holder. To view a copy of this licence, visit http://creativecommons.org/licenses/by/4.0/.

\section{References}

1. SEOM. Las cifras del cáncer en España 2019. Madrid: Sociedad Española de Oncología Médica; 2019. p. 24.

2. Casamayor M, Morlock R, Maeda H, Ajani J. Targeted literature review of the global burden of gastric cancer. Ecancermedicalscience. 2018;12:883.

3. McColl $\mathrm{K}$. What is causing the rising incidence of esophageal adenocarcinoma in the West and will it also happen in the East? $\mathrm{J}$ Gastroenterol. 2019;54:669-73.

4. Laks S, Meyers MO, Kim HJ. Surveillance for gastric cancer. Surg Clin N Am. 2017;97:317-31.

5. Baiocchi GL, Marrelli D, Velato G, Morgagni P, Giacopuzzi $\mathrm{S}$, Coniglio A, et al. Follow-up after gastrectomy for cancer: an appraisal of the Italian research group for gastric cancer. Ann Surg Oncol. 2014;21:2005-111.

6. Bass AJ, Thorsson VV, Shmulevich I, Reynolds SM, Miller M, Bernard B, et al. Comprehensive molecular characterization of gastric adenocarcinoma. Nature. 2014;513(7517):202-9.

7. Cristescu R, Lee J, Nebozhyn M, Kim K-M, Ting JC, Wong SS, et al. Molecular analysis of gastric cancer identifies subtypes associated with distinct clinical outcomes. Nat Med. 2015;21(5):449-56.

8. Lei Z, Tan IB, Das K, Deng N, Zouridis H, Pattison S, et al. Identification of molecular subtypes of gastric cancer with different responses to PI3-kinase inhibitors and 5-fluorouracil. Gastroenterology. 2013;145(3):554-65.

9. Jiménez-Fonseca P, Carmona-Bayonas A, Hernández R, Custodio A, Cano JM, Lacalle A, et al. Lauren subtypes of advanced gastric cancer influence survival and response to chemotherapy: real-world data from the AGAMENON National Cancer Registry. Br J Cancer. 2017;117(6):775-82.

10. Custodio A, Carmona-Bayonas A, Jiménez-Fonseca P, Sánchez ML, Viudez A, Hernández R, et al. Nomogram-based prediction of survival in patients with advanced oesophagogastric adenocarcinoma receiving first-line chemotherapy: a multicenter prospective study in the era of trastuzumab. Br J Cancer. 2017;116(12):1526-35.

11. Abbas M, Faggian A, Suntali DN, Khan GJ, Naeem S, Shi M, et al. Current and future biomarkers in gastric cancer. Biomed Pharmacother. 2018;103:1688-700.

12. Cardoso R, Coburn N, Seevaratnam R, Sutradhar R, Lourenco LG, Mahar A, et al. A systematic review and met-analysis of the utility of EUS for preoperative staging for gastric cancer. Gastric Cancer. 2012;15(Suppl 1):S19-26.

13. Smyth E, Schöder H, Strong VE, Capanu M, Kelsen DP, Coit DG, et al. A prospective evaluation of the utility of 2-Deoxy-2-(18F) Fluoro-D-glucose positron emission tomography and computed 
tomography in staging locally advanced gastric cancer. Cancer. 2012;118:5481-8.

14. Society of American Gastrointestinal and Endoscopic Surgeons (SAGES). Guidelines for diagnostic laparoscopy (web page). Los Angeles: SAGES; 2010.

15. Jiang L, Yang KH, Guan QL, Zhao P, Chen Y, Tian JH. Survival and recurrence free benefits with different lymphadenectomy for resectable gastric cancer: a meta-analysis. J Surg Oncol. 2013;107:807-14

16. Schuhmacher C, Gretschel S, Lordick F, Reichardt P, Hohenberger $\mathrm{W}$, Eisenberger CF, et al. Neoadjuvant chemotherapy compared with surgery alone for locally advanced cancer of the stomach and cardia: European Organisation for Research and Treatment of Cancer randomized trial 40954. J Clin Oncol. 2010;28:5210-8.

17. Stahl M, Walz MK, Stuschke M, Lehmann N, Meyer HJ, RieraKnorrenschild J, et al. Phase III comparison of preoperative chemotherapy compared with chemoradiotherapy in patients with locally advanced adenocarcinoma of the esophagogastric junction. J Clin Oncol. 2009;27:851-6.

18. Shapiro J, van Lanschot JJB, Hulshof MCCM, van Hagen P, van Berge Henegouwen MI, Wijnhoven BPL, et al. Neoadjuvant chemoradiotherapy plus surgery versus surgery alone for oesophageal or junctional cancer (CROSS): long-term results of a randomised controlled trial. Lancet Oncol. 2015;16:1090-8.

19. Cunningham D, Allum WH, Stenning SP, Thompson JN, Van de Velde CJ, Nicolson M, et al. Perioperative chemotherapy versus surgery alone for resectable gastroesophageal cancer. $\mathrm{N}$ Engl $\mathrm{J}$ Med. 2006;355(1):11-20.

20. Ychou M, Boige V, Pignon JP, Conroy T, Bouché O, Lebreton $\mathrm{G}$, et al. Perioperative chemotherapy compared with surgery alone for resectable gastroesophageal adenocarcinoma: an FNCLCC and FFCD multicenter phase III trial. J Clin Oncol. 2011;29(13):1715-21.

21. Al-Batran SE, Hofheinz RD, Pauligk C, Kopp HG, Haag GM, Luley KB, et al. Histopathological regression after neoadjuvant docetaxel, oxaliplatin, fluorouracil, and leucovorin versus epirubicin, cisplatin, and fluorouracil or capecitabine in patients with resectable gastric or gastro-esophageal junction adenocarcinoma (FLOT4-AIO): results from the phase 2 part of a multicentre, open-label, randomised phase $2 / 3$ trial. Lancet Oncol. 2016;17(12):1697-708.

22. Al-Batran SE, Homann N, Pauligk C, Goetze TO, Meiler J, Kasper $\mathrm{S}$, et al. Perioperative chemotherapy with fluorouracil plus leucovorin, oxaliplatin, and docetaxel versus fluorouracil or capecitabine plus cisplatin and epirubicin for locally advanced, resectable gastric or gastro-esophageal junction adenocarcinoma (FLOT4): a randomised, phase 2/3 trial. Lancet. 2019;393(10184):1948-57.

23. Group G, Paoletti X, Oba K, Michiels S, Ohashi Y, Pignon JP, et al. Benefit of adjuvant chemotherapy for resectable gastric cancer: a meta-analysis. JAMA. 2010;303:1729-37.

24. Sasako M, Sakuramoto S, Katai H, Kinoshita T, Furukawa $\mathrm{H}$, Yamaguchi T, et al. Five-year outcomes of a randomized phase III trial comparing adjuvant chemotherapy with S-1 versus surgery alone in stage II or III gastric cancer. J Clin Oncol. 2011;29:4387-93.

25. Smalley SR, Benedetti JK, Haller DG, Hundahl SA, Estes NC, Ajani JA, et al. Updated analysis of SWOG-directed intergroup study 0116: a phase III trial of adjuvant radiochemotherapy versus observation after curative gastric cancer resection. J Clin Oncol. 2012;30:2327-33.

26. Park SH, Sohn TS, Lee J, do Lim H, Hong ME, Kim KM, et al. Phase III trial to compare adjuvant chemotherapy with capecitabine and cisplatin versus con- current chemoradiotherapy in gastric cancer: final report of the adjuvant chemoradiotherapy in stomach tumors trial, including survival and subset analyses. J Clin Oncol. 2015;33:3130-6.

27. Cunningham D, Starling N, Rao S, Iveson T, Nicolson M, Coxon $\mathrm{F}$, et al. Upper gastrointestinal clinical studies group of the National Cancer Research Institute of the United Kingdom Capecitabine and oxaliplatin for advanced esophagogastric cancer. N Engl J Med. 2008;358(1):36-46.

28. Kang Y, Kang WK, Shin DB, Chen J, Xiong J, Wang J, et al. Capecitabine/cisplatin versus 5-fluorouracil/ cisplatin as first-line therapy in patients with advanced gastric cancer: a randomised phase III non inferiority trial. Ann Oncol. 2009;20(4):666-73.

29. Van Cutsem E, Moiseyenko VM, Tjulandin S, Majlis A, Constenla $\mathrm{M}$, Boni C, et al. Phase III study of docetaxel and cisplatin plus fluorouracil compared with cisplatin and fluorouracil as first-line therapy for advanced gastric cancer: a report of the V325 Study Group. J Clin Oncol. 2006;24(31):4991-7.

30. Bang YJ, Van Cutsem E, Feyereislova A, Chung HC, Shen L, Sawaki A, et al. Trastuzumab in combination with chemotherapy versus chemotherapy alone for treatment of HER2-positive advanced gastric or gastro-oesophageal junction cancer (ToGA): a phase 3, open-label, randomised controlled trial. Lancet. 2010;376(9742):687-97.

31. Tabernero J, Van Cutsem E, Bang Y-J, Fuchs ChS, Wyrwicz L, Lee KW, et al. Pembrolizumab with or without chemotherapy versus chemotherapy for advanced gastric or gastroesophageal junction (G/GEJ) adenocarcinoma: The phase III KEYNOTE-062 study. J Clin Oncol. 2019;suppl; abstr LBA4007:37.

32. Wilke H, Muro K, Van Cutsem E, Oh SC, Bodoky G, Shimada $\mathrm{Y}$, et al. Ramucirumab plus paclitaxel versus placebo plus paclitaxel in patients with previously treated advanced gastric or gastro-oesophageal junction adenocarcinoma (RAINBOW): a double-blind, randomised phase 3 trial. Lancet Oncol. 2014;15(11):1224-355.

33. Shitara K, Doi T, Dvorkin M, Mansoor W, Arkenau HT, Prokharau A, et al. Trifluridine/tipiracil versus placebo in patients with heavily pretreated metastatic gastric cancer (TAGS): a randomised, double-blind, placebo-controlled, phase 3 trial. Lancet Oncol. 2018;19(11):1437-48.

34. Le D, Fuchs CS, Doi T, Jang RW, Muro K, Satoh T, Machado $\mathrm{M}$, et al. Safety and efficacy of pembrolizumab monotherapy in patients with previously treated advanced gastric and gastroesophageal junction cancer: phase 2 clinical KEYNOTE-059 trial. JAMA Oncol. 2018;4(5):e180013-e180013180013.

Publisher's Note Springer Nature remains neutral with regard to jurisdictional claims in published maps and institutional affiliations. 